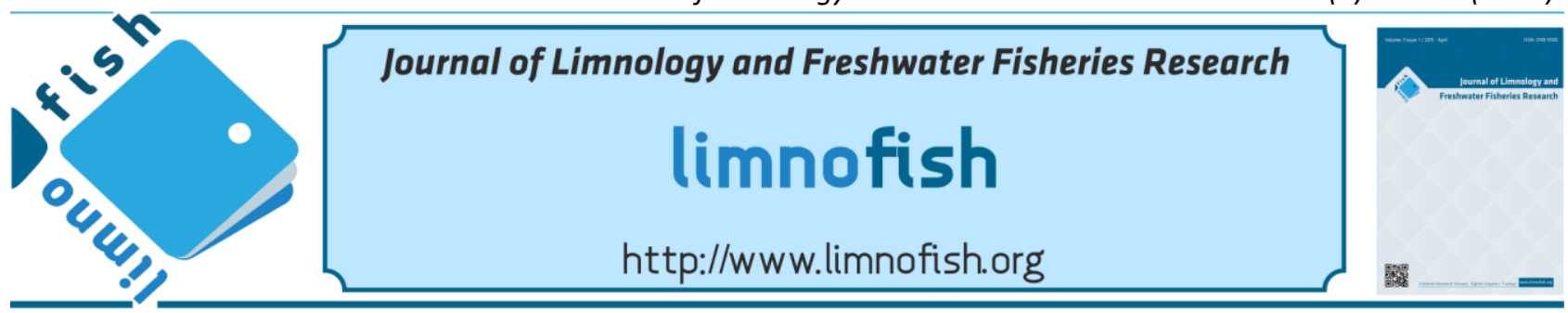

\title{
Büyükçekmece Rezervuarı (İstanbul, Türkiye)'ndaki Bazı Balık Türlerinin Boy-Ağırlık ve Boy-Boy İlişskileri ile Kondisyon Faktörleri
}

\author{
Gülşah SAÇ 1,* Hacer OKGERMAN $^{2}$ \\ ${ }^{1}$ İstanbul Üniversitesi, Fen Bilimleri Enstitüsü, 34134, Vezneciler, Fatih, İstanbul, Türkiye \\ 2 İstanbul Üniversitesi, Su Ürünleri Fakültesi, 34470, Laleli, Fatih, İstanbul, Türkiye
}

\section{$\ddot{O} z$}

$\mathrm{Bu}$ çalışmada, Büyükçekmece Rezervuarı'nda yaşayan 11 tatlısu balığı türünün boy-ağırlık ve boy-boy ilişkileri ile kondisyon faktörü değerleri tespit edilmiştir. Balık örnekleri, Mart 2009 ve Şubat 2010 tarihleri arasında farklı ă̆ göz açıklıklarına sahip galsama ağları ile aylık olarak yakalanmıştır. Balık türlerinin boy-ağırlık ilişkilerinden elde edilen $b$ değerleri $2,727 \pm 0,020$ ile 3,381 $\pm 0,001$ arasında değişmiştir. Kondisyon faktörü en düşük $0,74 \pm 0,08$ olarak $C$. taenia türünde ve en yüksek $1,72 \pm 0,15$ olarak $C$. gibelio türünde tespit edilmiştir.

Anahtar kelimeler: Cyprinidae, boy-ağırlık ilişkisi, kondisyon faktörü, boy-boy ilişkisi, büyüme.

\section{MAKALE BILGISI}

KISA MAKALE
$\begin{array}{ll}\text { Geliş } & : 22.01 .2016 \\ \text { Düzeltme } & : 31.03 .2016 \\ \text { Kabul } & : 06.04 .2016 \\ \text { Yayım } & : 20.04 .2016\end{array}$

DOI: 10.17216/LimnoFish-5000169386

* SORUMLU YAZAR

gulsahsac@gmail.com

Tel : +905553512569

Length-Weight Relationship, Length-Length Relationship and Condition Factor of Some Fish Populations in Büyükçekmece Reservoir (İstanbul, Turkey)

Abstract: In present study, length-weight relationship, length-length relationship and condition factor values were calculated for 11 freshwater fish species of Büyükçekmece Reservoir. Fish specimens were collected by gillnets having different mesh size between March 2009 and February 2010, monthly. The values of the exponent $b$ of the length-weight relationships varied between $2.727 \pm 0.020$ and $3.381 \pm 0.001$. The lowest mean condition factor was estimated $0.74 \pm 0.08$ for $C$. taenia while the highest value was recorded as $1.72 \pm 0.15$ in C. gibelio.

Keywords: Cyprinidae, length-weight relationship, condition factor, length-length relationship, growth.

Saç G, Okgerman H. 2016. Büyükçekmece Rezervuarı (İstanbul, Türkiye)'ndaki Bazı Balık Türlerinin Boy-Ağırlık ve Boy-Boy İlișkileri ile Kondisyon Faktörleri. LimnoFish. 2(1):43-48. doi: 10.17216/LimnoFish-5000169386

\section{Giriş}

İstanbul İli için en önemli içme ve kullanma suyu kaynaklarından biri olan Büyükçekmece Rezervuarı, Karasu Deresi'nin Marmara Denizi'ne döküldüğü yerde oluşmuş bir lagün gölüdür. İSKİ (İstanbul Su ve Kanalizasyon İdaresi) tarafindan 1985 'te inşa edilen ve 11,4 m yüksekliğindeki toprak dolgu ile deniz bağlantısı kesilen göl (Özuluğ 1999), zaman içerisinde tatlı su özelliği kazanmıştır. Yaklaşık \%o25 (Acara ve Gözenalp 1959)'ten ortalama \%00,2 (Saç 2010)'ye düşen tuzluluk değeri ile birlikte gölün balık faunası hızlı bir şekilde değişerek, denizel balık türlerinin yerini tatlı su balıkları almıştır. Göl balıkları ile ilgili olarak geçmişten günümüze kadar yapılan araştırmalar incelendiğinde, ilk kez Ninni
(1923) tarafindan Esox lucius Linnaeus, 1758 türünün göldeki varlığına değinilmiş, ardından Devedjian (1926) gölde yaşayan bazı balık türleri (kaya balığ1, yılan balığ kayası, tatlısu levreği) ve avcılıklarında kullanılan av araçları hakkında bilgi vermiştir. Takip eden yıllarda Kosswig ve Battalgil (1942), Acara ve Gözenalp (1959), Erman (1959) ve Balık (1985) da yaptıkları çalışmalarda gölde yaşayan bazı balık türlerine değinmişlerdir. Gölün balık faunasının tespitine yönelik ilk çalışma Meriç (1986) tarafından yapılmış ve bu çalışma ile hem deniz hem de tatlı su balıklarına ait toplam 30 tür tespit edilmiştir. Son olarak, Özuluğ (1999) tarafından yapılan revizyon çalışması ile göldeki denizel türlerin yerini tatlı ve acı 
su balıklarının aldığı belirlenmiş ve Türkiye içsuları için yabanc1 bir tür olan Carassius gibelio (Bloch, 1782) ile birlikte gölde toplam 23 balık türünün yaşadığg bildirilmiştir.

Mevcut literatür bilgisi ışığında, günümüze kadar yapılan çalışmaların çoğu gölün balık faunasının tespitine yöneliktir. Bununla birlikte, gölde yaşayan balık türlerinin biyolojilerine yönelik çalışmaların oldukça sınırlı olduğu görülmektedir (Erman 1959; Tarkan vd. 2006; Saç 2012; Saç ve Okgerman 2015). Mevcut çalışma ile, Büyükçekmece Rezervuarı'nda yaşayan bazı balık türlerinin boy-ağırlık ve boy-boy ilişkileri ile kondisyon faktörlerinin belirlenmesi amaçlanmiştır.

\section{Materyal ve Metot}

Saha çalışmaları, Mart 2009 ve Şubat 2010 tarihleri arasında aylık olarak gerçekleştirilmiştir. Balık avcılığında, farklı ağ göz açılıklarına sahip galsama ağları $(10 \times 10 \mathrm{~mm}, 20 \times 20 \mathrm{~mm}, 30 \times 30 \mathrm{~mm}$, $40 \times 40 \mathrm{~mm}$ ve $50 \times 50 \mathrm{~mm}$ ) kullanılmıştır. Akşam saatlerinde göle bırakılan ağlar, gölde yaklaşık 12 saat bekletildikten sonra, sabah ayn1 saatlerde toplanmıştır.

Yakalanan balıkların total boyları $0,1 \mathrm{~cm}$ hassasiyette ölçülmüş ve vücut ağırlıkları $0,01 \mathrm{~g}$ hassasiyette tartılmıştır. Türlere ait boy-ağırlık ilişkisinin hesaplanmasında aşağıda verilen denklemden yararlanılmıştır;

$W=a L^{b}$ (Le Cren 1951; Froese 2006).

Formüldeki $W$ vücut ağırlığını, $L$ total boyu, $a$ ve $b$ ise regresyon sabitlerini ifade etmektedir. Elde edilen $b$ değerinin izometrik büyümeden $(b=3)$ farklı olup olmadığ 1 t-test' i kullanılarak test edilmiştir (Zar 1999). Ayrıca $b$ değerinin \%95 güven aralığının (\%95CI) hesaplanmasında aşağıda verilen denklemden yararlanılmıştır;
$\% 95 C I=b \pm\left(t_{0,05(n-2)} * S H\right)$

SH=b'nin standart hata değeri (King 2007).

Toplam boy (TL), çatal boy (FL) ve standart boy (SL) arasındaki boy-boy ilişkileri doğrusal regresyon analizi kullanılarak hesaplanmıştır.

Kondisyon faktörünün hesaplanmasinda ise Fulton'un Kondisyon Faktörü eşitliğinden yararlanılmıştır;

$K=\left(W / L^{3}\right) \times 100($ Ricker 1975).

\section{Bulgular}

Çalışma süresince, 6 familyaya ait toplam 13 balık türü yakalanmıştır; Alburnus istanbulensis Battalgil, 1941, Carassius gibelio (Bloch,1782), Cyprinus carpio Linnaeus, 1758, Petroleuciscus borysthenicus (Kesler,1859), Rhodeus amarus (Bloch, 1782), Rutilus rutilus (Linnaeus,1758), Scardinius erythrophthalmus (Linnaeus, 1758), Vimba vimba (Linnaeus,1758), Clupeonella cultriventris (Nordmann, 1840), Cobitis taenia Linnaeus,1758, Esox lucius Linnaeus, 1758, Neogobius melanostomus (Pallas, 1814) ve Perca fluviatilis Linnaeus,1758. Ancak E. lucius ve $N$. melanostomus türlerine ait parametreler, örnek yetersizliğinden dolayı hesaplanmamıştır.

Türlere ait boy-ağırlık ilişkisi parametreleri $(a, b)$ ve kondisyon faktörü $(K)$ değerleri Çizelge 1'de gösterilmektedir. Buna göre, boy-ağırlık ilişkilerinden elde edilen $b$ değerleri 2,727 $\pm 0,020$ ile $3,381 \pm 0,001$ arasında değişmiş; büyüme tipleri ile ilgili olarak incelenen türlerin boy-ağırlık ilişkisinin allometrik bir büyüme gösterdiği $(p<0,05)$ tespit edilmiştir. Kondisyon faktörü değeri en düşük $0,74 \pm 0,08$ olarak $C$. taenia türünde ve en yüksek $1,72 \pm 0,15$ olarak $C$. gibelio türünde tespit edilmiştir. Boy-boy ilişkisini gösteren lineer regresyon analizi sonuçları ise Çizelge 2'de gösterilmektedir .

Çizelge 1. Büyükçekmece Rezervuarı'ndan yakalanan türlere ait büyüme parametreleri.

\begin{tabular}{lccccccccc}
\hline Balık türü & $n$ & $a$ & $b$ & $\begin{array}{c}\% 95 C I(b) \\
\text { (min.-mak.) }\end{array}$ & $r^{2}$ & $\begin{array}{c}\text { Büyüme } \\
\text { tipi }\end{array}$ & $\begin{array}{c}T L, c m \\
\text { (min.-mak.) }\end{array}$ & $\begin{array}{c}W, g \\
\text { (min.-mak.) }\end{array}$ & $K \pm \mathrm{SS}$ \\
\hline A. istanbulensis & 30 & 0,007 & 3,097 & $3,085-3,109$ & 0,986 & $\mathrm{~A}(+)$ & $7,8-27,3$ & $4,17-269,40$ & $1,04 \pm 0,12$ \\
C. carpio & 19 & 0,009 & 3,185 & $3,175-3,195$ & 0,993 & $\mathrm{~A}(+)$ & $10,6-32,0$ & $18,45-619,90$ & $1,65 \pm 0,21$ \\
C. cultriventris & 117 & 0,016 & 2,727 & $2,707-2,747$ & 0,786 & $\mathrm{~A}(-)$ & $7,2-10,0$ & $3,33-8,39$ & $0,93 \pm 0,08$ \\
C. gibelio & 395 & 0,012 & 3,110 & $3,108-3,112$ & 0,994 & $\mathrm{~A}(+)$ & $9,9-34,5$ & $16,17-774,40$ & $1,72 \pm 0,15$ \\
C. taenia & 11 & 0,011 & 2,796 & $2,675-2,917$ & 0,666 & $\mathrm{~A}(-)$ & $9,3-11,5$ & $5,81-10,44$ & $0,74 \pm 0,08$ \\
$P$. borysthenicus & 49 & 0,013 & 2,974 & $2,953-2,995$ & 0,918 & $\mathrm{~A}(-)$ & $6,5-9,8$ & $3,95-11,91$ & $1,28 \pm 0,10$ \\
$P$. fluviatilis & 689 & 0,006 & 3,256 & $3,254-3,258$ & 0,992 & $\mathrm{~A}(+)$ & $5,9-29,3$ & $1,37-449,00$ & $1,24 \pm 0,21$ \\
R. amarus & 1477 & 0,017 & 2,837 & $2,830-2,844$ & 0,710 & $\mathrm{~A}(-)$ & $5,3-8,2$ & $1,83-7,66$ & $1,29 \pm 0,15$ \\
R. rutilus & 1861 & 0,004 & 3,381 & $3,380-3,382$ & 0,992 & $\mathrm{~A}(+)$ & $6,3-32,5$ & $2,53-561,00$ & $1,08 \pm 0,03$ \\
S. erythrophthalmus & 305 & 0,008 & 3,173 & $3,169-3,177$ & 0,981 & $\mathrm{~A}(+)$ & $6,9-27,0$ & $4.04-344,00$ & $1,38 \pm 0,22$ \\
V. vimba & 258 & 0,006 & 3,144 & $3,141-3,147$ & 0,991 & $\mathrm{~A}(+)$ & $7,1-27,3$ & $3,66-269,40$ & $0,99 \pm 0,09$ \\
\hline
\end{tabular}

n:birey sayısı, $a$ ve $b$ : regresyon sabitleri, \%95CI: $b^{\prime}$ nin \%95 güven aralığ1, SH: $b^{\prime}$ nin standart hatası, $r^{2}:$ korelasyon katsayıs1, TL: total balık boyu, W: balık ağırlığı, K: kondisyon faktörü, SS: standart sapma, $A(+)$ : pozitif allometrik büyüme, $A(-)$ : negatif allometrik büyüme 
Çizelge 2. Büyükçekmece Rezervuarı'ndan yakalanan türlere ait boy-boy ilişkisi değerleri.

\begin{tabular}{lccccccc}
\hline \multirow{2}{*}{ Balık türü } & $\mathrm{n}$ & \multicolumn{3}{c}{$\mathrm{FL}=a \mathrm{TL}+b$} & \multicolumn{3}{c}{ SL $=a \mathrm{TL}-b$} \\
\cline { 3 - 7 } & & $a$ & $b$ & $r^{2}$ & $a$ & $b$ & $r^{2}$ \\
\hline A. istanbulensis & 30 & 0,912 & 0,000 & 0,998 & 0,809 & 0,182 & 0,996 \\
C. carpio & 19 & 0,887 & 0,065 & 0,998 & 0,794 & 0,404 & 0,996 \\
C. cultriventris & 117 & 0,946 & $-0,402$ & 0,914 & 0,819 & 0,168 & 0,922 \\
C. gibelio & 395 & 0,912 & $-0,045$ & 0,998 & 0,767 & 0,185 & 0,996 \\
C. taenia & 11 & - & - & - & 0,972 & 1,239 & 0,970 \\
$P$. borysthenicus & 49 & 0,907 & 0,156 & 0,990 & 0,768 & $-0,248$ & 0,946 \\
$P$. fluviatilis & 689 & 0,957 & $-0,079$ & 0,999 & 0,815 & 0,192 & 0998 \\
R. amarus & 1477 & 0,911 & 0,028 & 0,975 & 0,774 & $-0,058$ & 0,931 \\
R. rutilus & 1861 & 0,899 & $-0,010$ & 0,999 & 0,765 & $-0,054$ & 0,998 \\
S. erythrophthalmus & 305 & 0,910 & $-0,127$ & 0,995 & 0,784 & 0,081 & 0,994 \\
V. vimba & 258 & 0,891 & $-0,108$ & 0,997 & 0,806 & 0,559 & 0,995 \\
\hline
\end{tabular}

n:birey sayısı, $a$ ve $b$ : regresyon sabitleri, $r^{2}$ : korelasyon katsayısı, TL: total boy, FL: çatal boy, SL: standart boy

\section{Tartışma ve Sonuç}

Tarkan vd. (2006) tarafindan Marmara Bölgesi'nde yaşayan tatlısu balık populasyonlarının boy-ağırlık ilişkilerinin incelendiği çalışmada, Büyükçekmece Rezervuarı'nda yaşayan bazı balık türlerine ait $b$ değerleri bildirilmiştir (Çizelge 3). Buna göre, $C$. cultriventris, $C$. taenia, $R$. amarus, $R$. rutilus, $S$. erythrophthalmus ve $P$. fluviatilis türlerinin pozitif allometrik büyüme, $A$. istanbulensis türünün ise negatif allometrik büyüme gösterdiği görülmektedir (Tarkan vd. 2006). Mevcut çalışmanın bulgularına göre ise A. istanbulensis, $R$. rutilus, $S$. erythrophthalmus ve $P$. fluviatilis türleri pozitif allometrik büyüme gösterirken, $C$. cultriventris, $C$. taenia ve $R$. amarus türleri negatif allometrik büyüme göstermiştir. Her iki çalışmanın bulguları karşılaştırıldığında, özellikle $C$. cultriventris, $C$. taenia, $R$. amarus ve A. istanbulensis türleri için tespit edilen farklı büyüme tiplerinin, incelenen örneklerin boy ve ağırlık dağılımı, birey sayısı, yakalandığı dönem, cinsiyet durumu, gonad ve sindirim kanallarının doluluk oranları, muhafaza şekli gibi farklı etkenlere bağlı olabileceği düşünülmektedir.

Büyükçekmece Rezervuarı'nda yaşayan türlerden C. carpio, $C$. gibelio, $R$. rutilus ve S. eryhrophthalmus türlerinin besililik durumunun göstergesi olan kondisyon faktörü değerlerinin, farklı habitatlar için daha önceki çalışmalarda elde edilen kondisyon faktörü değerlerinin bazılarından daha yüksek, bazılarından ise daha düşük olduğu görülmektedir (Çizelge 4). Bununla birlikte, A. istanbulensis, C. cultriventris, $C$. taenia, $P$. borysthenicus, $P$. fluviatilis, $R$. amarus ve $V$. vimba türleri için ise daha önce kondisyon faktörü değerlerinin bildirildiği herhangi bir çalışmaya rastlanmamıştır. Kondisyon faktörü, yaş, eşey, eşeysel olgunluk, sindirim kanalı ve gonadların durumu, habitat, örnek sayısı, örneklerin boy ve ağırlık dağılımı gibi pek çok faktörün etkisi altında değişebilmektedir (Abowei 2009; Y1lmaz vd. 2010; Ayo-Olalusi, 2014). Kondisyon faktörünün, rezervuarda yaşayan bazı balık türleri için iyi iken bazıları için düşük değer vermesinin, türlerin kendilerine özgü morfolojik yapılarının yanı sıra ortamda bulunan besin kaynaklarından faydalanma oranları ile de ilişkili olabileceği düşünülmektedir.

Mevcut çalışma sonuçlarının, farklı boy ölçümleri kullanılan diğer çalışmaların sonuçları ile karşılaştırılmasında kolaylık sağlaması amacıyla hesaplanan boy-boy ilişkilerine göre, elde edilen korelasyon katsayıları (Çizelge 2), türlerin total, çatal ve standart boy ölçümleri arasında kuvvetli doğrusal ilişkiler olduğunu göstermektedir.

Çizelge 3. Büyükçekmece Rezervuarı'nda daha önce yapılan çalışma ile mevcut çalışmada elde edilen $b$ değerleri.

\begin{tabular}{lcc}
\hline Balık türü & Tarkan vd. 2006 & Mevcut çalışma \\
\hline C. cultriventris & $3,38 \pm 0,0343(\mathrm{n}: 20)$ & $2,727 \pm 0,020(\mathrm{n}: 117)$ \\
C. taenia & $3,34 \pm 0,0450(\mathrm{n}: 23)$ & $2,796 \pm 0,121(\mathrm{n}: 11)$ \\
A. istanbulensis & $2,73 \pm 0,0080(\mathrm{n}: 21)$ & $3,097 \pm 0,012(\mathrm{n}: 30)$ \\
R. amarus & $3,40 \pm 0,0536(\mathrm{n}: 14)$ & $2,837 \pm 0,007(\mathrm{n}: 1477)$ \\
R. rutilus & $3,33 \pm 0,0022(\mathrm{n}: 22)$ & $3,381 \pm 0,001(\mathrm{n}: 1861)$ \\
S. erythrophthalmus & $3,21 \pm 0,0026(\mathrm{n}: 19)$ & $3,173 \pm 0,004(\mathrm{n}: 305)$ \\
P. fluviatilis & $3,20 \pm 0,0136(\mathrm{n}: 11)$ & $3,256 \pm 0,002(\mathrm{n}: 689)$ \\
\hline
\end{tabular}


Çizelge 4. Cyprinus carpio, C. gibelio, R. rutilus ve S. erythrophthalmus türlerinin yaşadığ 1 farklı habitatlar için verilen kondisyon faktörü değerleri.

\begin{tabular}{|c|c|c|c|c|c|}
\hline Tür & Çalışma Sahası & $n$ & Boy dağılımı & $K$ & Literatür \\
\hline \multirow{13}{*}{ C. carpio } & Gölhisar Gölü (Burdur) & 693 & $10,5-49,4$ & 1,60 & Alp ve Balık 2000 \\
\hline & Karamık Gölü (Afyonkarahisar) & 108 & $9,0-70,0$ & 2,02 & Balık vd. 2006 \\
\hline & Bayramiç Baraj Gölü (Çanakkale) & 351 & $12,8-47,9$ & 2,66 & Çolakoğlu ve Akyurt 2011 \\
\hline & Liman Gölü (Samsun) & 288 & $14,5-46,0$ & 1,87 & Demirkalp 2007 \\
\hline & Çamlıgöze Baraj Gölü (Sivas) & 27 & $16,6-52,4$ & $1,64 *$ & Dirican ve Çilek 2012 \\
\hline & Almus Baraj Gölü (Tokat) & 308 & $14,0-36,0$ & $1,33 *$ & Karataş vd. 2007 \\
\hline & Gelingüllü Baraj Gölü (Yozgat) & 407 & $11,7-63,8$ & 2,34 & Kırankaya ve Ekmekçi 2004 \\
\hline & Damsa Baraj Gölü (Nevşehir) & 160 & $17,1-69,2$ & $1,62 *$ & Mert ve Bulut 2014 \\
\hline & Mogan Gölü (Ankara) & 364 & $14,0-41,5$ & 1,99 & Saylar ve Benzer 2014 \\
\hline & Karasu Çayı (Van) & 297 & $10,4-44,3$ & 2,12 & Şen ve Elp 2009 \\
\hline & Işıklı Gölü (Denizli) & 158 & $11,8-80,0$ & 1,92 & Yağc1 vd. 2008 \\
\hline & Hirfanlı Baraj Gölü (Kırşehir) & 456 & $11,8-57,4$ & 1,42 & Y1lmaz vd. 2007 \\
\hline & Bafra Balık Gölleri (Samsun) & 155 & $20,8-48,8$ & 1,87 & Y1lmaz vd. 2012 \\
\hline \multirow{9}{*}{ C. gibelio } & Beyşehir Gölü (Konya-Isparta) & 482 & $7,1-27,4$ & 2,21 & Cinar vd. 2007 \\
\hline & Gelingüllü Baraj Gölü (Yozgat) & 344 & $5,6-27,0$ & 2,40 & Kırankaya ve Ekmekçi 2013 \\
\hline & Eğirdir Gölü (Isparta) & 1717 & $7,5-33,3$ & 2,34 & Özkök vd. 2007 \\
\hline & İznik Gölü (Bursa) & 3114 & $7,8-32,2$ & 2,35 & Uysal vd. 2015 \\
\hline & Bafra Balık Gölü (Samsun) & 173 & $16,9-30,0$ & 2,49 & Bostanc1 vd. 2007a \\
\hline & Ula Göleti (Muğla) & 99 & $6,6-15,2$ & $1,48 *$ & Önsoy vd. 2011 \\
\hline & Buldan Baraj Gölü & 2325 & $9,7-25,5$ & 2,06 & Sar1 vd. 2008 \\
\hline & Aksu Nehri (Antalya) & 128 & $10,3-30,5$ & $1,96^{*}$ & İnnal 2012 \\
\hline & Büyük Menderes Havzası (Aydın) & 172 & $23,8-29,5$ & 2,45 & Şaş1 2015 \\
\hline \multirow{2}{*}{ R. rutilus } & Seyhan Baraj Gölü (Adana) & 157 & $13,5-24,0$ & 1,44 & Ergüden vd. 2008 \\
\hline & Sapanca Gölü (Adapazarı) & 907 & - & $1,14^{*}$ & Tarkan 2006 \\
\hline \multirow{4}{*}{ S. erythrophthalmus } & Gölhisar Gölü (Burdur) & 99 & $12,0-19,8$ & 1,89 & Bostanc1 vd. 2007b \\
\hline & Uluabat Gölü (Bursa) & 650 & $9,9-25,2$ & 1,83 & Cinar vd. 2008 \\
\hline & Sapanca Gölü (Adapazarı) & 409 & $13,4-29,2$ & $1,24 *$ & Okgerman 2005 \\
\hline & Sapanca Gölü (Adapazarı) & 593 & - & $1,21 *$ & Tarkan 2006 \\
\hline
\end{tabular}

n:birey sayısı, *ölçümlerde total boy kullanılmıştır.

\section{Teşekkür}

$\mathrm{Bu}$ çalışma, İstanbul Üniversitesi Bilimsel Araştırma Projeleri Birimi tarafından 2799 numaralı proje ile desteklenmiştir. Çalışma, 14 Şubat 2015 tarihinde aramızdan ayrılan Doç. Dr. Hacer Okgerman'a adanmıştır. Laboratuar ve saha çalışmaları sırasında yardımlarından ötürü Yard. Doç. Dr. Özcan Gaygusuz, Başak Oğuz, Elif Ece Serezli ile Gizem Kotiloğlu'na ve saha çalışmalarımızdaki desteklerinden ötürü balıkçı Arif Paşa'ya teşekkür ederiz.

\section{Kaynaklar}

Abowei JFN. 2009. The Abundance, condition factor and length-weight relationship of Sardinella madernensis (Jenyns, 1842) from Nkoro River Niger Delta, Nigeria. Advance J Food Sci Technol. 1(1):66-71.

Acara A, Gözenalp F. 1959. The northern lagoons of the Sea of Marmara. General Fisheries Council for the Mediterranean, Proc Tec Pap. 5:235-239.

Alp A, Balık S. 2000. Growth conditions and stock analysis of the carp (Cyprinus carpio, Linnaeus 1758) populations in Gölhisar Lake. Turk J Zool. 24(3):291-304.

Ayo-Olalusi CI. 2014. Length-weight relationship, condition factor and sex ratio of African mud catfish (Clarias gariepinus) reared in flowthrough system tanks. JFAS. 9(5):430-434. doi: $10.3923 /$ jfas.2014.430.434
Balık İ, Çubuk H, Özkök R, Uysal R. 2006. Some characteristics and size of carp (Cyprinus carpio L., 1758) population in the Lake Karamık (Afyonkarahisar/Turkey). Turk J Fish Aquat Sci. 6(2):117-122.

Balık S. 1985. Trakya Bölgesi içsu balıklarının bugünkü durumu ve taksonomik revizyonu. Doğa Bil Derg. A2, 9(2):147-160.

Bostanc1 D, Polat N, Kandemir Ș, Yılmaz S. 2007a. Bafra Balık Gölü'nde yaşayan havuz balığı (Carassius gibelio Bloch, 1782)'nun kondisyon faktörü ve boyağırlık ilişkisinin belirlenmesi. SDU Fen Derg. 2(2):117-125.

Bostanc1 D, Y1lmaz S, Polat N. 2007b. Gölhisar Gölü (Burdur)'ndeki kızılkanat (Scardinius erythrophthalmus Linnaeus, 1758) populasyonunda yaş belirleme, boy-ağırlık ilişkisi ve kondüsyon faktörü üzerine bir araştırma. Türk Suc Yaş Derg. 5(8):99-107.

Çınar Ş, Çubuk H, Özkök R, Tümgelir L, Çetinkaya S, Erol KG, Ceylan M, 2007. Beyşehir Gölü'ndeki gümüşi havuz balığı (Carassius gibelio Bloch, 1782) populasyonunun büyüme özellikleri. Türk J Aqua Life. 3-5(5-8):401-409.

Çınar Ş, Küçükkara R, Ceylan M, Çubuk H, Erol KG, Akçimen U, Savaşer S, 2008. Uluabat Gölü'ndeki Kızlkanat (Scardinius erythrophthalmus L.,1758) populasyonunun büyüme parametrelerinin araştırılması. Ege Üni Su Ürün Derg. 25(4):289-293. 
Çolakoğlu S, Akyurt İ, 2011. Bayramiç Baraj Gölü'ndeki (Çanakkale) aynalı sazan (Cyprinus carpio L., 1758) balıklarının populasyon yapısı ve büyüme özellikleri. İÜ Su Ürün Derg. 26(1):27-46.

Demirkalp FY. 2007.Growth characteristics of carp (Cyprinus carpio L., 1758) in Liman Lake (Samsun, Turkey). Hacettepe J Biol Chem. 35(1):1-8.

Devedjian K. 1926. Peche et pecheries en Turquie. Imprimerie De L'Administration De La Dette Publique Ottomane, İstanbul, Turkey.

Dirican S, Çilek S. 2012. Condition factors of seven Cyprinid fish species from Çamligöze Dam Lake on central Anatolia, Turkey. African Journal of Agricultural Research. 7(31):4460-4464. doi: 10.5897/AJAR12.1187

Ergüden SA, Ergüden D, Göksu MZL. 2008. Seyhan Baraj Gölü'ndeki (Adana) kızılgöz (R. rutilus L., 1758)'un büyüme özellikleri. Journal of FisheriesSciences.com 2(1):77-87.

Erman F. 1959. Has kefal (Mugil cephalus L.)'ın biyolojisi. Hidrobiyoloji Mecmuas1, A, 5(1-4):62-86.

Froese R. 2006. Cube law, condition factor, weight-length relationships: history, meta-analysis and recommendations. J Appl Ichthyol. 22(4):241-253. doi: 10.1111/j.1439-0426.2006.00805.x

Innal D. 2012. Age and growth properties of Carassius gibelio (Cyprinidae) living in Aksu River Estuary (Antalya-Turkey). Rev Hydrobiol. 5(2):97-109.

Karataş M, Çiçek E, Başusta A, Başusta N. 2007. Age, growth and mortality of common carp (Cyprinus carpio Linneaus, 1758) population in Almus Dam Lake (Tokat- Turkey). J Appl Biol Sci.1(3):81-85.

Kırankaya ŞG, Ekmekçi FG. 2004. Gelingüllü Baraj Gölü'nde yaşayan aynalı sazan (Cyprinus carpio L., 1758)'ın büyüme özellikleri. Turk J Vet Anim Sci. 28(6):1057-1064.

Kırankaya ŞG, Ekmekçi FG. 2013. Life-history traits of the invasive population of prussian carp, Carassius gibelio (Actinopterigi: Cypriniformes: Cyprinidae), from Gelingüllü Reservoir, Yozgat, Turkey. Acta Ichthyol Piscat. 43(1):31-40. doi: 10.3750/AIP2013.43.1.05

Kosswig C, Battalgil F. 1942. Zoogeographie der Türkischen Süsswasserfische. İstanbul Üni Fen Fak Mecm. B,7(3):145-165.

Le Cren ED. 1951. The length-weight relationship and seasonal cycle in gonad weight and condition in the perch (Perca fluviatilis). J Anim Ecol. 20(2):201-218. doi: $10.2307 / 1540$

Meriç N. 1986. Fishes encountered in Büyükçekmece Lake, İstanbul. İstanbul Üniv Fen Fak Mecmuası. B, 51:41-46.

Mert R, Bulut S. 2014. Some biological properties of carp (Cyprinus carpio L., 1758) introduced into Damsa Dam Lake, Cappadocia Region, Turkey. Pakistan J Zool., 46(2):337-346.

Ninni E. 1923. Primo contributo allo studio dei pesci e della pesca nelle acque dell'Impero
Ottomano, 5, Premiate Officine Grafiche Carlo Ferrari, Venezia.

Okgerman H. 2005. Seasonal variations in the length-weight relationship and condition factor of rudd (Scardinius erythrophthalmus L.) in Sapanca Lake. Int J Zool Res. 1(1):6-10. doi: 10.3923/ijzr.2005.6.10

Önsoy B, Filiz H, Tarkan AS, Bilge G, Tarkan AN. 2011. Occurrence of non-native fishes in a small man-made lake (Lake Ula, Muğla): Past, present, future perspectives. Turk J Fish Aquat Sci. 11(2):209-215. doi: 10.4194/trjfas.2011.0205

Özkök R, Çubuk H, Tümgelir L, Uysal R, Çınar Ş, Küçükkara R, Erol KG, Ceylan M. 2007. Eğirdir Gölü'ndeki Gümüşi Havuz Balığı (Carassius gibelio Bloch, 1782) Populasyonunun Büyüme Özellikleri. Turk Sucul Yaş Derg. 3-5(5-8): 313-322.

Özuluğ M. 1999. A taxonomic study on the fish in the basin of Büyükçekmece Dam Lake. Turk J Zool. 23(4):439-451.

Ricker WE. 1975. Computations and interpretation of biological statics of fish populations. Bulletin of the Fisheries Research Board of Canada. Bulletin 191. $382 \mathrm{pp}$.

Saç G. 2010. Büyükçekmece Baraj Gölü'ndeki İsrail sazanı Carassius gibelio (Bloch, 1782)'nun büyümesi ve üremesi [Yüksek Lisans Tezi]. İstanbul Üniversitesi. $69 \mathrm{~s}$.

Saç G. 2012. Büyükçekmece Rezervuarı (İstanbul)'nda yaşayan Clupeonella cultriventris (Nordmann, 1840)'in bazı biyolojik özellikleri. İstanbul Üni $\mathrm{Su}$ Ürün Derg. 27(2):23-33.

Saç G, Okgerman H. 2015. Growth and reproduction of a non-native fish species Carassius gibelio (Bloch, 1782) from Büyükçekmece Lake (İstanbul, Turkey). IUFS J Biol. 74(1): (baskıda).

Sarı HM, Balık S, Ustaoğlu MR, İlhan A. 2008. Population structure, growth and mortality of Carassius gibelio (Bloch, 1782) in Buldan Dam Lake. Turk J Fish Aquat Sci. 8(1):25-29.

Saylar Ö, Benzer S. 2014. Age and growth characteristics of carp (Cyprinus carpio L., 1758) in Mogan Lake, Ankara, Turkey. Pakistan J Zool. 46(5):1447-1453.

Şaşı H. 2015. Growth and condition of invasive species prussian carp, Carassius gibelio (Bloch, 1782) in a dam lakes from Büyük Menderes basin (Turkey). Muğla. J Sci Tec. 1(2):6-10.

Şen F, Elp M. 2009. Karasu Çayı (Van) sazan (Cyprinus carpio L., 1758) populasyonunun baz1 biyolojik özellikleri. Biyol Bil Araş Derg. 2(1):31-34.

Tarkan AS. 2006. Reproductive ecology of two cyprinid fishes in an oligotrophic lake near the southern limits of their distribution range. Ecol Freshw Fish. 15(2):131-138. doi: 10.1111/j.1600-0633.2006.00133.x

Tarkan AS, Gaygusuz Ö, Acıpınar H, Gürsoy Ç, Özuluğ M, 2006. Length-weight relationship of fishes from the Marmara region (NW-Turkey). J Appl Ichthyol. 22(4):271-273. doi: 10.1111/j.1439-0426.2006.00711.x 
Uysal R, Alp A, Yeğen V, Apaydın Yağcı M, Çetinkaya $\mathrm{S}$, Yağc1 A, Bostan $\mathrm{H}$, Cesur M, Küçükkara R. 2015. İznik Gölü (Bursa/Türkiye)'ndeki gümüşi havuz balığının (Carassius gibelio Bloch, 1782) büyüme özellikleri. LimnoFish. 1(1):19-27. doi: 10.17216/LimnoFish-5000086696

Yağcı MA, Alp A, Yeğen V, Uysal R, Yağc1 A, Ceylan M. 2008. Işıklı Gölü'ndeki (Çivril-Denizli) sazan populasyonu (Cyprinus carpio L., 1758)'nun büyüme özellikleri. Ege Üni $\mathrm{Su}$ Ürün Derg. 25(4):337-341.

Yılmaz M, Gül A, Saylar Ö. 2007. Hirfanlı Baraj Gölü (Kırşehir)'nde yaşayan Cyprinus carpio L., 1758'nun büyüme özellikleri. GÜ Gazi Eğitim Fak Derg. 27(1):37-57.

Yılmaz S, Yazıcıŏlu O, Yılmaz M, Polat N. 2010. Hirfanlı Baraj Gölü'nde yaşayan Cyprinus carpio L., 1758 ve Tinca tinca (L., 1758)'nın boy-ağırlık ve boyboy ilişkileri ile mevsimsel kondisyon faktörleri. SDÜ J Sci (E-Journal). 5(2):154-162.

Yılmaz S, Yazıcıoğlu O, Polat N. 2012. Bafra Balık Gölleri (Samsun, Türkiye)'ndeki sazan (Cyprinus carpio L., 1758)'in yaş ve büyüme özellikleri. Karadeniz Fen Bil Der. 2(7):1-12.

Zar JH. 1999. Biostatistical Analysis, 4th edn. Upper Saddle River, New Jersey: Prentice Hall, 663 p. 